Ten samples of commercial feeds were used and the results obtained for each of these feeds, using the official method for the determination, appear above.

It can readily be seen from the above results that the new apparatus gave better extraction in the greatest number of cases, and averages higher in 8 out of the Io cases here noted. It was found, too, that there is a greater uniformity in the results obtained, it being necessary in several instances to make as many as six determinations with the straight extraction apparatus and four with the Soxhlet before checks within 0.2 per cent cottid be obtained.

To summarize, the apparatus gives better extraction than does either the straight extraction or the Soxhlet methods. It is easy to manipulate, presenting a smooth outer surface, reducing the danger of breakage to a minimum. The recovery of the solvent is easy and rapid and entails no loss of time. The cost of the apparatus is also comparatively small.

Acknowledgment should be made to Mr. A. P. Kerr, Assistant Director of this station, for his suggestions.

Louisiana Agricultural Experiment Station

Baton Rouge, Louistana

\section{A SIMPLE, DURABLE, ELECTRICALLY OPERATED GAS-VALVE}

By ZENO OSTENBERG

Received June, 21, 1915

The valve herewith illustrated was designed and built to regulate the flame of a double-burner gas-stove, which heated a large water bath 24 in. in diameter. Since two of them have been in operation for over a year and a half, with entire success, it was thought that a description and illustration of the mechanism would be useful to others.

The mechanism consists essentially of the "ironclad" electromagnet $A$, which lifts the iron disc $B$ to which is attached the brass valve and stem $C$. The brass valve $C$ makes a gas-tight fit with the main brass body $D$ at the inlet $E$ when no current is passing

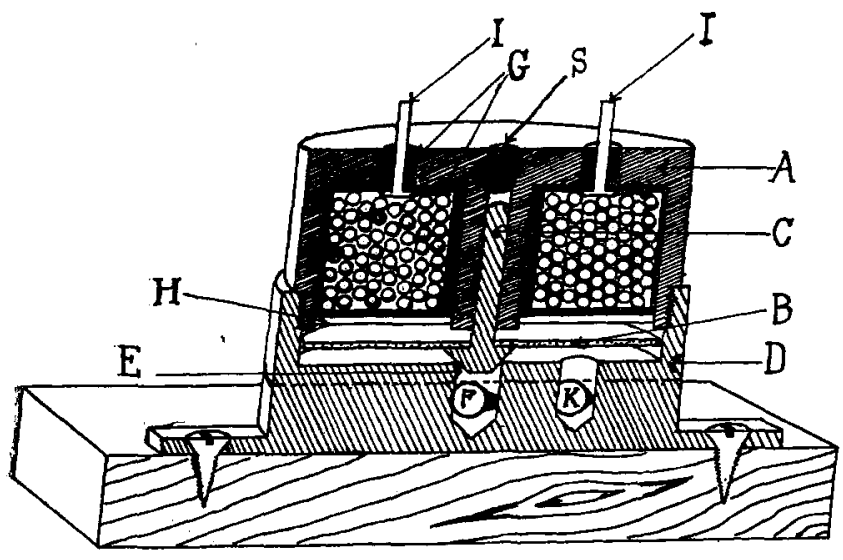

through the magnet winding, but when current is sent through the magnet winding, the disc $B$ and valve $C$ are raised and thus gas is allowed to pass from $E$ to $K$, which leads to the burner. $F$ is the outlet to a pilot light. The disc $B$ is prevented from sticking to the magnet $A$ by the plug $S$, which may be screwed down to limit the travel of the valve stem $C . G$ is insulation which must be able to withstand a rise of temperature up to about $100^{\circ}$, as the magnet sometimes becomes quite hot. The disc $H$ is of brass and is soldered gas-tight to the magnet $A$ to prevent moisture and gas from attacking the wiring and also to keep the wiring in place. The gas inlet tube (not shown) enters opposite to the pilot opening $F$. When operated from a $\mathrm{I}$ IO volt line, the winding consists of No. 26 d. c. c. copper wire with a 16 C. P. carbon lamp in series. This allows slightly less than 0.5 ampere to pass through the winding of the electromagnet. For use with a storage battery No. 30 wire is used.

The electrical circuit is opened and closed by a 75 ohm standard Pony relay, which is operated by a dry battery and thermoregulator. The dry batteries, which were originally put into the thermo-regulator circuits over a year and half ago, are still able to operate the relays as only about 0.02 ampere is used, and this amount of current is so small that no trouble whatever has been experienced from oxidation of the mercury at the contacts in the thermo-regulators.

Obviously the valve may be used on any size of burner, from the smallest micro-bunsen to one which has a gas inlet equal in size to the inlet and outlet of the valve. In the valves in use these holes are $0.25 \mathrm{inch}$ in diameter.

2233 Webster ST., SAN Francisco

\section{PORTABLE TITRATING TABLE \\ By R. E. OzIAS \\ Received June 16, 1915}

Fig. I shows a convenient portable titrating table which has recently been installed in the United States Appraiser's Laboratory at New York. The burettes are operated by compressed air supplied by a Goodyear air bottle which rests on a shelf attached to the table.

The air is conducted through $1 / 8$ in. and $1 / 4$ in. brass pipe to the main pipe ( $I$ in. diameter), on top of table, on which are seen the air pressure gauge and the individual taps fitted with $1 / 8$ Lunkenheimer brass spring key cocks.

The top of the table is $3 \mathrm{ft} . \times 6 \mathrm{ft}$. and is perforated with 8 circular openings, $5 \mathrm{in}$. in diameter, in which the bottles are placed, resting on a base board securely fastened 5 in. below the top.

The standard solution bottles are of dark glass, $2500 \mathrm{cc}$. capacity, and as shown are eight in number. Without necessarily increasing the size of the table, a second row of eight bottles could be placed in a similar position and thus give it a capacity of sixteen standard solutions.

No moisture or carbonic absorption apparatus is shown on the train, as the solutions employed did not require their use, but when necessary those accessories

1 Published with the consent of the Secretary of the Treasury and United States Appraiser, Port of New York. 